\title{
THE KEY LIMITING FACTORS FOR THE ESTABLISHMENT OF A BENCHMARKING PARTNERSHIP IN CLUSTER ENTERPRISES
}

\begin{abstract}
The benchmarking partnership of cluster enterprises is an important and interesting field of scientific research in the management sciences. The purpose of the paper is to identify the key factors limiting the establishment of this form of partnership and to establish their impact. This paper argues that proper identification of the main limiting factors is an essential management process to help with benchmarking partnerships, and I aim to examine which limiting factors (internal or external) have a greater negative impact on the establishment of benchmarking partnerships? The work utilizes indirect research through the analysis of literature sources and deductive reasoning, and direct research through the use of questionnaires conducted with selected Polish clusters enterprises.
\end{abstract}

Keywords: benchmarking partnership, best practices, cluster, limiting factors.

\section{INTRODUCTION}

Benchmarking partnership of cluster enterprises is an important and interesting field of scientific research, in particular in the context of the paradigms of relation and cooperation of enterprises, currently proposed in the management sciences (Szydełko, 2018a; Szydełko 2018b). A combination of three subjects of interest in the scientific and management field: partnership relations, clusters and benchmarking, gives a specific scope of research, encompassing benchmarking partnership of cluster companies.

A. Adamik (2013) claims that "for strategic management goals, partnering should be given a wider (strategic) interpretation, as an approach to management used by two or more organisations to achieve specified goals through an increase in the effectiveness of the resources of each party".

The partnership is a voluntary and dynamic inter-organisational relationship that reflects the essence of close cooperation between enterprises. It is a form of implementation of an inter-organisational win-win strategy in which all participants are winners. It requires the development of specific relations between partners, primarily based on such principles as: community of goals, mutual trust, commitment, exchange of information, actively and constantly seeking improvements and sharing tasks, risk, costs and benefits.

According to P. Morosini (2004), cluster is a "socioeconomic entity characterised by a social community of people and a population of economic agents localised in close

\footnotetext{
${ }^{1}$ Magdalena Szydełko, PhD, Department of Management Systems and Logistics, Faculty of Management, Rzeszow University of Technology, Powstańców Warszawy Ave. 10, 35-959 Rzeszów; e-mail: mszydel@ @rz.edu.pl. ORCID: 0000-0002-9661-3519.
} 
proximity in a specific geographic region”. Cluster participants ,work together in economically linked activities, sharing and nurturing a common stock of product, technical and organisational knowledge in order to generate superior products and services in the marketplace" (Morosini, 2004).

Clusters are made up not only of physical flows of inputs and outputs, but also involve intense exchange of business information, know-how, and technological expertise, both in traded and un-traded forms (Sölvell, 2008). Thus, cluster participants may establish long-term partnership cooperation in fulfilment of common projects and cluster initiatives resulting in improvement of market performance and competitiveness of involved partners.

The variety of definitions of benchmarking that appear in the literature is the result of the shift of emphasis to other elements used to describe this conceptual category by researchers and practitioners. According to S. Mohapatra (2012),

though the definitions highlight one aspect more than the other, more often any benchmarking is accepted as a process of continuous search for adaptation of significantly better practices that lead to superior performance by investigating the performance and practices of other organisations (benchmark partners).

It must be pointed out that benchmarking is not a method for copying the practices of competitors, but a way of seeking superior process performance by looking both inside and outside the industry. Benchmarking is a powerful tool for improvement in various fields of business activity. It refers to gathering information by the companies what others are doing, usually to evaluate whether they are operating efficiently or identify areas for improvement (Sharma, Iqbal, Victoriano, 2013). The term "benchmark" refers to the reference point against which performance is measured. It is the indicator of what can be achieved vis-à-vis what is being achieved (Mohapatra, 2012).

The review of the literature leads to a conclusion that the benchmarking partnership phenomenon has not been the subject of any previous in-depth scientific analyses. For the purposes of this paper, the term "benchmarking partnerships" shall mean "mutual beneficial exchange of best business practice information which should lead to improved performance for all the organisations involved" (Bendell, Boulter, Gatford, 1997). Therefore, benchmarking partnership is a form of partnership cooperation justified for the use by cluster companies because of its features that promote mutually beneficial exchange of information concerning the results achieved and the best practices they use in different areas of their activity.

None of the researchers has performed theoretical analyses in terms of the possibility of benchmarking adjustment to the needs of cluster members in the aspect of development of the inter-organisational partnership relations paradigm. The knowledge in this scope is very little. The concept of intra-cluster benchmarking was first used and explained by the Author of this paper (see Szydełko, 2015) and this issue has been developed by her in the Ph.D Thesis and monograph (see Szydełko, 2019).

For the purposes of this paper, the following theoretical interpretation of the concept of benchmarking partnership of enterprises within a cluster has been accepted: it is a process of mutual beneficial exchange of information between enterprises participating in a cluster, concerning their performance and best practices in various fields of activity, according to partnership rules. That leads to improvement of performance of the parties involved in the 
benchmarking process (micro level) and improvement of the cluster competitive advantage (meso level).

\section{OBJECTIVE AND METHODOLOGY}

In this paper, the Author intends to present the results of the empirical research focused on the recognition of the impact of internal and external limiting factors for establishment of benchmarking partnership by the Polish cluster enterprises.

The purpose of the paper is to identify and indicate the degree of impact of the key factors limiting the establishment of this specific form of partnership. The attempt to determine the key limiting factors is a response to the identified gap in the knowledge concerning that concept of partnership.

The thesis of the paper is the claim that proper identification of the catalogue of the main limiting factors for the establishment of benchmarking partnerships in the cluster is an essential part of the management process of this form of partnership. The following research problem has been formulated: which group of limiting factors (internal or external) has greater negative impact on the establishment of benchmarking partnerships in the cluster?

The purpose of the work has determined the research procedure. The theoretical part has been based on a research procedure that included indirect research focused on analysing literature sources and deductive reasoning. In the empirical part, the following quantitative research methods have been applied: direct research conducted among selected Polish cluster enterprises with the use of questionnaire techniques and statistical methods.

The survey questionnaire has been sent to 434 enterprises participating in 10 selected clusters having registered offices in the Subcarpathian Voivodeship in Poland. The clusters had been selected for the purposes of the direct research based on the following 6 criteria:

1. The cluster has at least one valid document confirming its existence.

2. The cluster has a defined and clear economic profile.

3. The cluster is characterised by varied structure of entities (at least 10 cluster members were required).

4. Cluster members actively and regularly contact each other.

5. The cluster has an active coordinator, who provides services for the benefit of the members.

6. Coordinator agrees to help in the dissemination of the research tool among the cluster members.

The data gathering stage was conducted from 2 November until 30 December 2016. Finally, 41 enterprises returned filled survey questionnaires, which gives the response rate of 9.45 percent.

\section{RESEARCH RESULTS AND DISCUSSION}

Considering the significance of limiting factors and their impact on the shape of intracluster benchmarking, internal (corporate) factors and external factors within the cluster and the benchmarking group are crucial. In case of external factors originating in the macro-environment, the impact on that form of cooperation of enterprises within the cluster is much weaker and less evident. That is why these factors were not included in further analysis.

As part of the conducted survey, the participants were asked to evaluate the strength of the negative effect of selected variables (42 limiting factors) on establishing benchmarking 
partnership within a cluster. In the survey questionnaire, the respondents used a 5-grade Likert scale, where 1 indicated very low negative impact, 2 - small negative impact, 3 - medium negative impact, 4 - high negative impact and 5 - very high negative impact.

For the purposes of an in-depth analysis focused on comparison of the degree of impact of a group of 20 internal and 22 external limiting factors on establishment of benchmarking partnership within a cluster, basic descriptive statistics have been determined. Table 1 presents a summary of classic measures, including arithmetic mean and standard deviation, calculated for all internal limiting factors (IL) and external limiting factors (EL) identified with the use of the research tool. In further considerations, the arithmetic mean of score will be referred to as the impact indicators of individual factors (IF). The summary is a ranking of 42 factors arranged in the order of decreasing arithmetic mean of score given by the surveyed Polish cluster enterprises. The factors have been arranged from the highest to the lowest score in terms of their negative impact on benchmarking partnership. The group of internal limiting factors is coloured in the table. Encouragingly, enterprises participating in the research were aware of the existence and impact on benchmarking partnership of not only internal, but also external factors.

Table 1. The ranking of limiting factors for benchmarking partnership of cluster members participating in the research

\begin{tabular}{|l|c|c|}
\hline \multicolumn{1}{|c|}{ Limiting factors for benchmarking partnership of Polish cluster } & $\begin{array}{c}\text { Arithmetic } \\
\text { mean (IF) }\end{array}$ & $\begin{array}{c}\text { Standard } \\
\text { deviation }\end{array}$ \\
\hline $\begin{array}{l}\text { IL-1. Negative attitude of the management towards the idea of learning } \\
\text { from peers within the cluster }\end{array}$ & 4.39 & 0.74 \\
\hline EL-21. Low level of mutual trust in a cluster & 4.32 & 0.76 \\
\hline EL-22. Negative experiences in cooperation within a cluster & 4.29 & 0.84 \\
\hline $\begin{array}{l}\text { IL-2. Narrow scope of knowledge of the leadership on benchmarking } \\
\text { partnership }\end{array}$ & 4.05 & 0.89 \\
\hline $\begin{array}{l}\text { IL-3. Negative attitude of benchmarking team members towards the idea } \\
\text { of learning from peers within the cluster }\end{array}$ & 4.05 & 0.74 \\
\hline IL-4. Low level of relational competence of the cluster enterprise & 4.05 & 0.95 \\
\hline IL-5. Management's fear of sharing information with competitors & 4.02 & 0.85 \\
\hline EL-23. Low level of social proximity of enterprises within the cluster & 4.02 & 0.99 \\
\hline EL-24. Lack of focus of potential benchmarking partners on reciprocity & 3.98 & 0.72 \\
\hline $\begin{array}{l}\text { EL-25. Lack of implementation of joint projects and undertakings } \\
\text { within the cluster }\end{array}$ & 3.93 & 1.08 \\
\hline $\begin{array}{l}\text { EL-26. Difficulties in obtaining consent from potential benchmark } \\
\text { partners for the exchange of information }\end{array}$ & 3.83 & 0.97 \\
\hline EL-27. Perceiving benchmarking partnership as high-risk cooperation & 3.78 & 0.99 \\
\hline EL-28. Mutual misunderstanding of benchmarking motives & 3.76 & 0.80 \\
\hline $\begin{array}{l}\text { EL-29. Lack of effective communication system supporting the } \\
\text { exchange of information within the cluster }\end{array}$ & 3.73 & 0.67 \\
\hline $\begin{array}{l}\text { IL-6. Lack of skills in transforming benchmarking information into } \\
\text { useful knowledge }\end{array}$ & 3.71 & 0.81 \\
\hline $\begin{array}{l}\text { IL-7. Lack of skills in in-depth recognition of strengths and weaknesses } \\
\text { against the benchmark }\end{array}$ & 3.68 & 0.91 \\
\hline IL-8. Conviction of cluster enterprise about its uniqueness & 3.68 & 0.85 \\
\hline
\end{tabular}


Table 1 (cont.). The ranking of limiting factors for benchmarking partnership of cluster members participating in the research

\begin{tabular}{|c|c|c|}
\hline $\begin{array}{l}\text { Limiting factors for benchmarking partnership of Polish cluster } \\
\text { enterprises }\end{array}$ & $\begin{array}{c}\text { Arithmetic } \\
\text { mean (IF) }\end{array}$ & $\begin{array}{l}\text { Standard } \\
\text { deviation }\end{array}$ \\
\hline $\begin{array}{l}\text { IL-9. Lack of knowledge about methods of selecting benchmarking } \\
\text { partners }\end{array}$ & 3.63 & 0.80 \\
\hline IL-10. Employees resistance to change and fear of the unknown & 3.59 & 1.14 \\
\hline IL-11. Employees fear of negative consequences of benchmarking & 3.59 & 1.14 \\
\hline IL-12. Too tight sticking to methods and solutions used in the industry & 3.59 & 1.05 \\
\hline EL-30. Divergence of benchmarking goals set by the cluster enterprises & 3.59 & 0.87 \\
\hline $\begin{array}{l}\text { IL-13. Narrow scope of knowledge of benchmarking team members on } \\
\text { benchmarking partnership }\end{array}$ & 3.54 & 0.78 \\
\hline $\begin{array}{l}\text { EL-31. Lack of symmetry in involvement of cluster enterprises in } \\
\text { fulfilment of benchmarking goals }\end{array}$ & 3.54 & 0.81 \\
\hline $\begin{array}{l}\text { EL-42. Lack of adaptation capability of enterprises in benchmarking } \\
\text { within the cluster }\end{array}$ & 3.46 & 1.10 \\
\hline $\begin{array}{l}\text { EL-33. Lack of guarantee of equal rights and benefits for benchmarking } \\
\text { partners }\end{array}$ & 3.34 & 1.13 \\
\hline $\begin{array}{l}\text { IL-14. Conviction of cluster enterprises about the simplicity of } \\
\text { benchmarking activities based on intuition }\end{array}$ & 3.24 & 0.86 \\
\hline $\begin{array}{l}\text { EL-34. Lack of symmetry in involvement of resources for } \\
\text { benchmarking purposes }\end{array}$ & 3.24 & 0.94 \\
\hline IL-15. Lack of experience in implementation of benchmarking & 3.20 & 0.98 \\
\hline $\begin{array}{l}\text { IL-16. Lack of experience in knowledge, information and internal } \\
\text { communication management }\end{array}$ & 3.07 & 0.91 \\
\hline $\begin{array}{l}\text { EL-35. Lack of balance between short-term and long-term } \\
\text { benchmarking goals }\end{array}$ & 3.00 & 0.71 \\
\hline $\begin{array}{l}\text { EL-36. Low level of organisational closeness of enterprises within the } \\
\text { cluster }\end{array}$ & 2.93 & 0.79 \\
\hline EL-37. Lack of IT tools in benchmarking & 2.90 & 1.02 \\
\hline $\begin{array}{l}\text { IL-17. Lack of skills in risk management in building relationships within } \\
\text { a cluster }\end{array}$ & 2.85 & 0.76 \\
\hline EL-38. Lack of cluster critical mass & 2.83 & 0.83 \\
\hline EL-39. Low level of cluster maturity & 2.83 & 0.83 \\
\hline EL-40. Low level of cognitive proximity of cluster members & 2.80 & 0.78 \\
\hline $\begin{array}{l}\text { IL-18. Lack of capability to cover the expenses related with } \\
\text { benchmarking within the cluster }\end{array}$ & 2.71 & 0.90 \\
\hline IL-19. Fear of being recognised as a copycat & 2.68 & 1.01 \\
\hline IL-20. Belief that imitation is unethical and shameful & 2.59 & 0.84 \\
\hline $\begin{array}{l}\text { EL-41. Low level of institutional closeness of enterprises within the } \\
\text { cluster }\end{array}$ & 2.49 & 0.98 \\
\hline $\begin{array}{l}\text { EL-42. Low level of geographic proximity of enterprises within the } \\
\text { cluster }\end{array}$ & 2.34 & 0.99 \\
\hline
\end{tabular}

Explanation: IL - internal limiting factor, EL - external limiting factor, IF - impact indicators of individual factors.

Source: Author's own work based on the research results. 
The analysis of values of impact indicators (IF) of individual limiting factors allows to distinguish a group of 8 factors (IL-1, EL-21, EL-22, IL-2, IL-3, IL-4, IL-5, EL-23) that in the respondents ' opinion had the greatest negative effect on establishing benchmarking partnership within a cluster ( $I F \geq 4.0$ ). It must be pointed out that the highest ranks belonged to: negative attitude of the management towards the idea of learning from peers within the cluster $(\mathrm{IF}=4.39)$, low level of mutual trust in a cluster $(\mathrm{IF}=4.32)$ and negative experiences in cooperation within a cluster $(\mathrm{IF}=4.29)$.

Not surprisingly, cluster enterprises' management attitudes towards the idea of learning from peers are key barriers for benchmarking partnership. A lot of reference sources tell that management attitude is critical in terms of implementation of various concepts and using management instruments.

In the identified group of key limiting factors of benchmarking partnership, recognised in cluster environment as external conditions, low level of trust between cluster enterprises is one of the major items. Presented outcomes lead to a conclusion that high degree of confidence would have positive effect on establishing that particular form of partnership, focused on mutual creative implementation of best practices in various fields of activity.

In the respondents'opinion, negative experience of cluster enterprises in cooperation with other network participants was also one of the key barriers undermining activity in benchmarking partnership. Any unfavourable events in the course of implementation of common cluster projects and undertakings are reflected in negative attitude of the management and other employees towards the idea of learning from peers. It is a certain internal barrier to establishing contacts with potential partners, both for the needs of informal and formal intra-cluster benchmarking.

The presented ranking of limiting factors for benchmarking partnership arranged from the highest to the lowest degree of negative impact allows the first attempt to explain the research problem formulated in this paper. Visual distinction of internal and external factor groups in Table 1 does not support the claim that corporate factors are leading in the prepared ranking. We may cautiously conclude that internal factors, unlike external conditions, have stronger negative effect on enterprises undertaking any activity in the field of benchmarking partnership within a cluster.

Fig. 1 presents the percentage of average score of the impact of internal and external limiting factors in 0.5 point intervals.

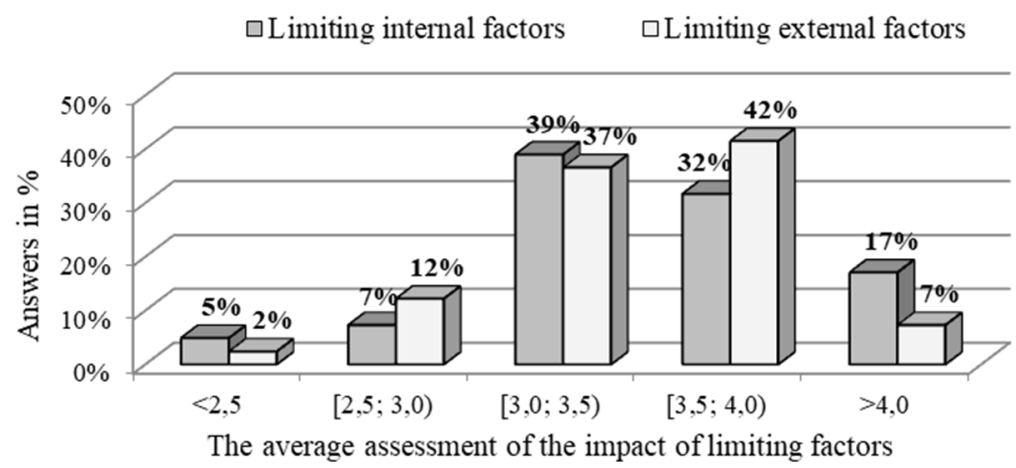

Fig. 1. Percentage of average score of the impact of internal and external limiting factors Source: Author's own work based on the research results. 
When analysing the results in form of a histogram, it can be concluded that average scores of both internal and external factors mostly fall within the interval of [3.0; 4.0). For 39\% of respondents, the average score of strength of internal factors falls within the interval of [3.0; 3.5). For $42 \%$ of respondents, the average score of strength of external factors falls within the interval of $[3,5 ; 4,0)$. This also does not allow to determine clearly which group of limiting factors (internal or external) has larger negative effect on establishing benchmarking partnerships within a cluster.

The comparison of average score of impact of internal and external limiting factors, determined for 41 survey participants, has been presented in form of a spread plot. The graphical representation of the results is shown in diagram 2. The horizontal axis represents the average score of internal factors, while the vertical axis refers to external factors. Cases (cluster enterprises) are represented as dots (dot markers). An additional y $=\mathrm{x}$ reference line allows to determine if the majority of analysed enterprises gave higher score to internal or external factors in terms of negative impact on establishing benchmarking partnership within a cluster. The dots on the spread plot representing survey participants who:

- reported higher negative impact of external factors are placed above the reference line,

- reported equal impact of both groups of factors are placed on the reference line,

- reported hither negative impact of internal factors are placed below the reference line.

Looking at the dots distribution on the plot, it is clear that most of them are located below the reference line. This spread indicates that most respondents attributed higher negative impact on establishing benchmarking partnership to internal factors, rather than external ones.

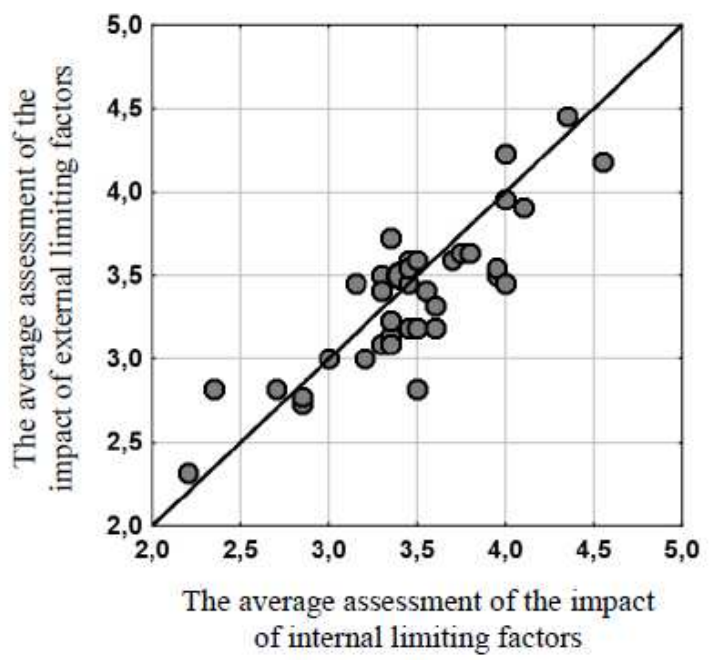

Fig. 2. Comparison of average assessments of the impact of internal and external limiting factors assigned to the Polish cluster enterprises surveyed

Source: Author's own work based on the research results.

The insight on the degree of influence of limiting factors will enable cluster enterprises with benchmark-partnering potential to create favourable partnership conditions more 
knowingly, overcome barriers and reduce the impact of negative factors. As soon as these entities become aware of the negative issues that hinder establishment of benchmarking partnership, it is reasonable to ${ }^{2}$ :

- take preventive action, focused on eliminating potential limitations,

- take correction, consisted in eliminating identified limitations,

- take corrective action, consisted in eliminating the causes of identified limitations.

The outcomes of the described research shall mostly concern managerial staff and other employees of cluster enterprises directly involved in cluster initiatives (collective projects and undertakings), or benchmarking specialists. It refers both to cluster enterprises that have already implemented benchmarking partnerships, both formally and informally, and those intending to knowingly participate in intra-cluster benchmarking partnership.

\section{CONCLUSIONS}

The concept of benchmarking partnership is undoubtedly a response to the needs of today's enterprises forming clusters, that search for solutions allowing to increase efficiency and effectiveness of performed processes, to improve the competitive advantage of their individual companies and the whole cluster. Thus the idea of intra-cluster benchmarking partnership is a new way of thinking about building competitiveness of enterprises within a cluster.

The purpose of the paper was to identify and idicate the degree of impact of key factors limiting the establishment of benchmarking partnership by the Polish cluster enterprises in the context of the empirical research. The indicated cognitive gap in the knowledge on the intra-cluster benchmarking based on partnership required a statistical data analysis. This paper shall contribute to filling this gap.

Considering the significance and strength of impact of limiting factors on building benchmarking partnership wihtin a cluster, the highest importance can be attributed not only internal conditions, but also external factors that occur within the cluster and the benchmarking group. However, in the light of empirical research, the internal limiting factors have greater negative impact on the establishment of benchmarking partnerships in the clusters than external limiting factors.

The key limiting factors for benchmarking partnership according to surveyed cluster enterprises include: negative attitude of the management towards the idea of learning from peers within the cluster, low level of mutual trust in a cluster, negative experiences in cooperation within a cluster, narrow scope of knowledge of the leadership on benchmarking partnership, negative attitude of benchmarking team members towards the idea of learning from peers within the cluster, low level of relational competence of cluster enterprises, management's fear of sharing information with competitors and low level of social proximity of enterprises within the cluster.

To conclude, it should be noted that appropriate building and development of benchmarking partnership within a cluster requires relevant methodological guidelines, including the knowledge of the internal and external limiting factors for establishment of this form of partnership. The considerations presented herein have confirmed the assumption that proper identification of the catalogue of main limiting factors for

\footnotetext{
${ }^{2}$ Nomenclature taken from qualitology.
} 
benchmarking partnerships in the cluster is an essential part of the management process in that form of partnership.

The effects of the research efforts include implications both for the management theory and the management practice in cluster enterprises. The author believes that the results of this research may become a new point of view in the continuing discussion of the management theoreticians specialised in inter-organisational relations management, benchmarking, clusters and knowledge management. These issues are also important in the practical perspective, since the number of cluster enterprises that shape the path of their strategic growth by building and developing relations with other entities, is increasing.

The author is quite sure that certain limitations could not be eliminated in the conducted study. These were mostly associated with the assumed methodological approach. But they can also be linked to unexpected interference in the course of the research procedure as well as certain circumstances hindering analysis of enterprises, often mentioned in the literature. The data collection process has been based on gathering respondents opinions, subjective by nature, which could also affect the quality and content of formulated conclusions. In the survey questionnaire, 5-grade scoring scales have been used, which is not without significance in terms of objectiveness of the results. Interpretation of scoring (despite attachment of relevant descriptions) may vary within the respondents group. Another critical limitation related to the methodology is that the outcomes of empirical study could not be generalised. It was due to the fact that only Polish clusters located in the Podkarpackie Voivodeship were chosen to participate in the study on cluster enterprises benchmarking partnership. The outcomes of the analysis, as well as related conclusions might be the starting point for further, in-depth empirical study.

\section{REFERENCES}

Adamik, A. (2013). A partnering approach to extending the business base through cooperation with competitors (coopetition) - is it an option for SMEs? [in:] Zaharim, A., Rodrigues, R.G., eds., Recent Advances in Management, Marketing and Finances. Cambridge: WSEAS Press.

Bendell, T., Boulter, L., Gatford, K. (1997). The Benchmarking Workout. London: Financial Times Pitman Publishing.

Mohapatra, S. (2012). Information Theory and Best Practices in the IT Industry. New York: Springer.

Morosini, P. (2004). Industrial Clusters, Knowledge Integration and Performance. "World Development", Vol. 32, No. 2. DOI: 10.1016/j.worlddev.2002.12.001.

Sharma, R.S., Iqbal, M., Victoriano, M.M. (2013). On the Use of Benchmarking and Good Practices for Knowledge Management for Development. "Knowledge Management Research \& Practice" 11(4). DOI: 10.1057/kmrp.2012.27.

Sölvell, Ö. (2008). Clusters - Balancing Evolutionary and Constructive Forces. Stockholm: Ivory Tower Publishing.

Szydełko, M. (2015). Ramy koncepcyjne zastosowania benchmarkingu w klastrze. Prace Naukowe Uniwersytetu Ekonomicznego we Wrocławiu, No. 399.

(2018a). A Conceptual Framework for Intra-Cluster Benchmarking Partnership [in:] Albrychiewicz-Słocińska, A., Czarnecka, A., Dunay, A., eds., Challenges of Management in Modern Organizations. Gödöllö: Szent István Egyetemi Kiadó Nonprofit Kft.

- (2018b). Internal and External Facilitating Factors for Establishment of Benchmarking Partnership by the Cluster Enterprises in the Context of the Empirical Research - the Case of 
Poland [in:] Slavíčková, P., Talášek, T., eds., Knowledge for Market Use 2018: Public Finances in the Background of Sustainable Development. International Scientific Conference Proceedings, Olomouc: Palacky University Olomouc [Access: 22.11.2019]. Access on the internet: http://knowledgeconference.upol.cz/downloads/2018-Knowledge_for_Market_Use_ Proceedings.pdf.

(2018c), The Essence and Attributes of Inter-Organizational Relations. "Humanities and Social Sciences" No. 4. DOI: 10.7862/rz.2018.hss.89.

— (2019). Partnerstwo benchmarkingowe przedsiębiorstw $w$ klastrze jako kategoria relacji międzyorganizacyjnych. Warszawa: CeDeWu.

DOI: $10.7862 /$ rz.2020.hss.35

The text was submitted to the editorial office: January 2020.

The text was accepted for publication: September 2020. 